\title{
Mapping the risks of Peste des Petits Ruminants spread in the Republic of Kazakhstan
}

\author{
Sarsenbay Abdrakhmanov ${ }^{1}$, Yersyn Mukhanbetkaliev ${ }^{1}$, Akhmetzhan Sultanov ${ }^{2}$, Gulzhan \\ Yessembekova $^{1}$, Sergey Borovikov ${ }^{1}$, Aidar Namet ${ }^{2}$, Abdykalyk Abishov ${ }^{3}$, Andres Perez ${ }^{4}$, \\ and Fedor Korennoy ${ }^{5}$ \\ ${ }^{1} \mathrm{~S}$ Seifullin atyndagy Kazak agrotekhnikalyk universiteti \\ ${ }^{2}$ Kazakh Research Veterinary Institute \\ ${ }^{3}$ LTD NPC DiaVak-ABN \\ ${ }^{4}$ University of Minnesota \\ ${ }^{5}$ Federal Center for Animal Health FGBI 'ARRIAH'
}

October 1, 2020

\begin{abstract}
Peste des petits ruminants (PPR) is a viral transboundary disease of small ruminants that causes significant damage to agriculture. The disease has not been previously registered in the Republic of Kazakhstan (RK). This paper presents an assessment of the susceptibility of the RK territory to the spread of this disease in case of its importation from infected countries. Ordinary Least Squares (OLS) and Geographically Weighted Regression (GWR) models trained on the PPR outbreaks in China were used to rank municipal districts of the RK in terms of the risk of PPR spread. Spatial density of outbreaks was used as a risk indicator while a number of socio-economic, landscape and climatic indicators were considered as explanatory variables. The Exploratory Regression tool was used to reveal a best combination of independent variables based on specified thresholds of R-squared, variables' multicollinearity and residuals' normality and autocorrelation. The small ruminants' density, the maximum green vegetation fraction, the annual mean temperature, the road length and density as well as the cattle density were the most significant factors. Both OLS and GWR demonstrated nearly similar model performance providing a global adjusted R-squared of 0.61. Applied to the RK, the models show the greatest risk of PPR spread in the south-eastern and northern regions of the country, especially within Almaty, Zhambyl, Turkistan, West Kazakhstan and East Kazakhstan regions. As part of the study, a country-wise survey was carried out to collect data on the distribution of livestock population the RK, which resulted in compiling a complete geo-database of small ruminants' holdings in the country. The research results can be used to form a national strategy for the prevention of the importation and spread of PPR in Kazakhstan through targeted monitoring in high-risk areas.
\end{abstract}

\begin{abstract}
Peste des petits ruminants (PPR) is a viral transboundary disease of small ruminants that causes significant damage to agriculture. The disease has not been previously registered in the Republic of Kazakhstan (RK). This paper presents an assessment of the susceptibility of the RK territory to the spread of this disease in case of its importation from infected countries. Ordinary Least Squares (OLS) and Geographically Weighted Regression (GWR) models trained on the PPR outbreaks in China were used to rank municipal districts of the RK in terms of the risk of PPR spread. Spatial density of outbreaks was used as a risk indicator while a number of socio-economic, landscape and climatic indicators were considered as explanatory variables. The Exploratory Regression tool was used to reveal a best combination of independent variables based on specified thresholds of R-squared, variables' multicollinearity and residuals' normality and autocorrelation.
\end{abstract}


The small ruminants' density, the maximum green vegetation fraction, the annual mean temperature, the road length and density as well as the cattle density were the most significant factors. Both OLS and GWR demonstrated nearly similar model performance providing a global adjusted R-squared of 0.61 . Applied to the RK, the models show the greatest risk of PPR spread in the south-eastern and northern regions of the country, especially within Almaty, Zhambyl, Turkistan, West Kazakhstan and East Kazakhstan regions. As part of the study, a country-wise survey was carried out to collect data on the distribution of livestock population the RK, which resulted in compiling a complete geo-database of small ruminants' holdings in the country. The research results can be used to form a national strategy for the prevention of the importation and spread of PPR in Kazakhstan through targeted monitoring in high-risk areas.

Keywords : Peste des Petits Ruminants, Republic of Kazakhstan, Ordinary Least Squares regression, Geographically Weighted Regression, Explanatory Regression, ArcGIS.

\section{Introduction}

The preservation of sustainable epizootic welfare of the country's livestock in relation to threats caused by especially dangerous diseases, such as Peste des petits ruminants (PPR), is the most important task of veterinary science and practice, which is of paramount importance in protecting the health and life of people, providing the population with high-grade and safe food products, and providing industry with quality raw materials.

PPR is a highly contagious viral disease that affects small ruminants and causes $30 \%$ to $70 \%$ mortality among the infected animals (Mahapatra et al., 2006; http://www.fao.org/ppr/en/). Due to the significant socio-economic damage and negative impact on food security in many countries of the world, PPR is included in the list of priority diseases of the Five-Year Plan of Action of the FAO / OIE World Framework Program for the progressive control of transboundary animal diseases aimed at PPR elimination by 2030 (Global Strategy for the Control and Eradication of PPR, 2015). The high degree of this disease's presence among countries close to Kazakhstan provides a need to analyze the threat of importation and subsequent spread of PPR in the country (Ahaduzzaman, 2020).

PPR is a typical transboundary disease: first reported in West Africa, 1942, the disease has steadily expanded its range over the years. So, in the period from 2001 to 2011, the disease spread in 56 countries: 35 in Africa and 21 in Asia (Munir, 2015), and by 2016 it was registered in more than 70 countries and became endemic in the regions of Northern and Eastern and West Africa, the Near and Middle East, South, Central Asia and Western Eurasia (Balamurugan et al., 2014; Bouchemla et al., 2018; Zhuravlyova et al., 2020). These regions are home to more than $80 \%$ of the world's sheep and goats; products such as goat's milk, lamb and wool play a huge role in the welfare of many families. FAO estimates that about 300 million small farming families worldwide depend on small ruminants because sheep and goats are critical assets for poor rural households, providing them with protein, milk, fertilizer and wool, and often representing substantial social capital and access to financial loans (Global Strategy for the Control and Eradication of PPR, 2015).

According to official information provided by the OIE, the epizootic situation with PPR in the world remains rather tense (OIE WAHIS, 2020). Despite intense international, regional and national efforts to combat the disease, most developing countries around the world are non-free from PPR, constituting a constraint to free, liberal global trade in animals and livestock products (http://www.fao.org/ppr/en/).

The PPR epizootic situation in the Central Asia countries neighboring Kazakhstan is ambiguous. Thus, in Armenia, Azerbaijan and Turkmenistan, outbreaks of PPR have not been previously registered, however monitoring studies and preventive vaccination of 33-70\% of animals susceptible to PPR in risk zones are being carried out (Koshemetov et al., 2014; Amirbekov et al., 2020). In Uzbekistan and Kyrgyzstan, isolated outbreaks of the disease were previously recorded, and active monitoring and preventive vaccination are currently being carried out (Yapici et al., 2014; Fine et al., 2020).

The disease annually leads to large economic losses. For example, a series of epidemics in Kenya in 20062008 caused death of 1.2 million small ruminants, resulting in losses of more than US $\$ 23.5$ million, and milk 
production declining by 2.1 million liters. In general, the annual damage from PPR is estimated at US $\$$ 1.4-2.1 billion (Kihu et al., 2015; Jones et al., 2016; Bardhan et al., 2017).

For the successful prevention of PPR, regional studies of the epizootic process are important, which will allow to study the features of its manifestation in a specific territory, in specific natural-geographical and socio-economic conditions, with subsequent forecasting as a reliable foundation for managing the epizootic process through the development and implementation of effective contra-epizootic measures.

According to the official data of the State Veterinary Service of the RK, PPR has never been registered in the country before, although there are some publications indicating the isolation of PPR pathogen from sick sheep and goats in the RK in 2003 and 2014 (Lundervold et al., 2004; Kock et al., 2015). Socioeconomic, organizational, structural and geopolitical changes in Kazakhstan during post-Soviet time, as well as the expansion of international trade, economic and cultural ties lead to additional risks of importation of dangerous infectious diseases' pathogens into its territory, including through cross-border areas. The Republic of Kazakhstan is historically characterized by unique natural conditions for the preservation of the activity of many known and the formation of new focal areas that can cause a sudden aggravation of the epizootic situation in the region.

The purpose of this research is the assessment of the susceptibility of the RK territory to the PPR spread, treated as risk of PPR spread in case of the pathogen importeation into the country.

\section{Materials and methods}

2. Study area

The area of interest for modeling the risk of PPR spread was the entire territory of the Republic of Kazakhstan (RK, Kazakhstan). RK is a land-locked state in Central Asia, occupying an area of 2,725,000 km² with a population of 18.28 million. Administratively, the RK is divided into 14 units of the first level - regions ("oblasts"). Each of the regions in turn, is sub-divided into second-level administrative units - districts, whose area ranges from 283 to 138,663 $\mathrm{km}^{2}$ (mean of $15,780 \mathrm{~km}^{2}$ ). Totally, there are 173 districts in the RK (Fig. 1).

PPR outbreaks in People's Republic of China (PRC, China) were used to train regression models. Total area of China is 9,598,962 $\mathrm{km}^{2}$, while population exceeds 1,404.328 million. The second (prefectural) level of administrative divisions is presented by 333 units with an area from 490 to $473,671 \mathrm{~km}^{2}$ (mean of 27,670 $\left.\mathrm{km}^{2}\right)$.

In terms of area, China occupies the third place in the world, while Kazakhstan - the ninth place. Both countries share a land border of more than $1,600 \mathrm{~km}$.

$<$ Figure 1 about here $>$

Modeling method

Since the RK is currently free from PPR, no outbreaks were available to validate any internally built model. Thus, to rank Kazakhstan districts as to the risk of PPR spread, a regression model trained on outbreaks in China was applied. Two types of regression were considered, namely Ordinary Least Squares (OLS) and Geographically Weighted Regression (GWR). These models reveal a quantitative relationship between the indicator under study (dependent variable) and a set of potential influencing factors expressed as geographic variables. The key difference between the two models is that GWR looks for local variation of the study relationships by estimating regressions within a certain area around each feature thus allowing to account for non-stationarity of variables (Brunsdont et al., 1998).

Second level administrative units (districts in Kazakhstan, counties or prefectures in China) were chosen as the analysis units for creating a regression model. For each unit, the number of PPR outbreaks, number of infected animals and explanatory factors were extracted (see below).

To build the regression model, the following epidemic indicators per administrative unit were tested as a 
dependent variable: 1) the total number of PPR outbreaks; 2) the density of outbreaks per unit area; 3) the total number of infected animals; 4) the PPR prevalence. To normalize distribution of the candidate dependent variables, we used log-transformed values.

The following geographically distributed landscape, climatic and socio-economic characteristics for each administrative unit were selected as potential explanatory factors based on the analysis of scientific publications on PPR spatial and temporal modeling (Ma et al., 2017, 2019; Mokhtari et al., 2017; Cao et al., 2018; Gao et al., 2019; Ruget et al., 2019): 1) total road length; 2) road density; 3) average small ruminants density; 4) average cattle density; 5) average population density; 6) average elevation; 7) annual mean temperature; 8) annual precipitation; 9) maximum green vegetation fraction. Measurement units and data sources are shown in Table 1.

$<$ Table 1 about here $>$

The pre-selection of dependent and independent variables was performed using the Exploratory Regression procedure (ArcGIS, Esri). This procedure iteratively fits multiple ordinary least squares regression models (OLS) using various combinations of potential explanatory variables and provides a recommendation for choosing the optimal combination based on a set of statistical metrics, which include Akaike's Information Criterion (AIC), Adjusted R-squared $\left(\mathrm{R}^{2}\right)$ and Variance Inflation Factor (VIF). Besides, regression residuals are checked for normality using Jarque-Bera test, and for spatial autocorrelation using Moran's I test. A combination of dependent and independent variables was chosen that provided the lowest AIC, $\mathrm{R}^{2}>0.5$, VIF $<2$, Jarque-Bera p-value $>0.1$ (that does not allow rejecting the null-hypothesis about residuals' normality) and SA p-value $>0.1$ (that does not allow rejecting the null-hypothesis about residuals' spatial randomness) (Mitchell, 2005).

Further, the OLS and GWR were both fitted using the selected combination of dependent and independent variables. For GWR, the adaptive kernel radius was chosen determined by the input features density based on cross validation (Fotheringham et al., 2002). The quality of the models' fit was assessed using the global adjusted R-squared and AIC. Residuals were tested for spatial autocorrelation by means of Global Moran's I test. The best model was chosen that provides a lower AIC, higher $\mathrm{R}^{2}$ and demonstrate random spatial distribution of residuals.

The regression coefficients of the resulting model were further used to build a predictive model for the entire model region including China and Kazakhstan. Predicted spatial PPR outbreaks' density values for Kazakhstan were ranked in four classes by quantiles conventionally named as 'very low', 'low', 'medium' and 'high risk', and mapped using a choropleth method.

\section{Data sources}

Data on PPR outbreaks in China for the period 2007 - 2020 (as of 30.08.2020) were obtained from the FAO EMPRES-I database (http://empres-i.fao.org/eipws3g/). During this period, 289 PPR outbreaks were registered in the China (Fig. 2). For 248 (86\%) of these outbreaks, the OIE is indicated as a source of data, while the rest $14 \%$ are attributed to "national authorities". Of those outbreaks, the vast majority $(258 ; 89 \%)$ were recorded in 2014. Within each outbreak, a number of infected animals ranges from one to 3290 with a mean of 152 .

$<$ Figure 2 about here $>$

Detailed data on the small ruminants' distribution in Kazakhstan were obtained during the national wise survey undertaken by the research team members in 2018 - 2019. The survey included a series of expeditionary trips coordinated with regional veterinary authorities. During the survey, complete information was collected about livestock farms in the RK, including geographic coordinates and the population size that enables mapping the livestock population at any required level of spatial resolution. A total of 2,478 small ruminants holdings (farms) were georeferenced with 18 to 167,918 (mean 8,988) animals. The total population of small ruminants in the RK thus sums up to $22,271,628$ head providing a district-level density 
of zero to 277 (mean 9 ) head $/ \mathrm{km}^{2}$. The density of small ruminants' population at the district level overlaid with the farms' locations is presented in Figure 1.

\section{Software}

Data processing, geospatial analysis and visualization were conducted using ArcMap Desktop 10.8.1 geographic information system with an extension Spatial Analyst (Esri, USA).

\section{Results and discussion}

2. Selection of dependent and independent variables

Testing of various combinations of dependent and independent variables using the Exploratory Regression procedure has shown that the best results are obtained by using the log-transformed PPR outbreaks' density per unit area as a dependent variable, as well as: road length and density, small ruminants density, maximum green vegetation fraction, annual mean temperature and cattle density as explanatory variables. This combination of variables provided Jarque-Bera p-value of 0.104 and Spatial Autocorrelation p-value of 0.868 with VIF of 1.378 and was further used to build the OLS and GWR models.

Fitting the regression models

Both OLS and GWR models demonstrated nearly similar performance in explaining the PPR distribution in China with OLS providing slightly lower AIC (table 2). Testing the residuals using the Moran's I global autocorrelation tool returned low z-values with high p-values that suggests residuals' spatial distribution close to a normal one and allows speaking of a fairly good fit of the models. A kernel radius for the GWR model was set to include 123 nearest features that comprises all Chinese prefectures with PPR outbreaks thus making the GWR model virtually identical to the OLS one. For the further modeling, the OLS was used.

$<$ Table 2 about here $>$

Table 3 shows the regression coefficients of the OLS model. For each coefficient, the standard error and the standardized value of the coefficient are also indicated, which enables clear comparison between the relative contribution of each variable.

$<$ Table 3 about here $>$

Analysis of the obtained coefficients allows making conclusions about the largest contribution of the vegetation index (MGVF) that demonstrated a positive relation with the dependent variable, so that more vegetation was found to be more suitable to the PPR spread, which is obviously explained by higher number of small ruminants in vegetated areas. The road length showed a negative influence on the outbreaks' density while road density had a positive effect, which may suggest the higher suitability of pastoral regions with poorly developed road network, and potentially be resulted by a bias introduced by prevailing PPR outbreaks reporting from smaller and densely populated prefectures of China. Small ruminants density was also among the most contributing factors demonstrating a positive relation with the PPR, which can be naturally thought as an indicator of contact rate between herds. Annual mean temperature was found to be positively associated with the PPR density that may suggest higher suitability of warmer areas to small ruminants breeding, particularly that using open pastures. The least important predictor was a cattle density, which is negatively associated with the density of PPR outbreaks. This may be explained by the competitive use of pasture areas by both species: taking into account the technology of their keeping, feeding and characteristics of pastures, cattle and small ruminants are mostly bred in different regions, therefore the presence of cattle may indicate an insignificant number of small ruminants, and vise versa.

\section{Extrapolation of the model to the entire model territory}

Using the obtained coefficients (Table 3), the OLS model was extrapolated to the entire territory of China and Kazakhstan. We excluded administrative units of 'cities' type, which normally do not have small ruminants population, but may result in overprediction because of relatively small area and high road 
density. The resulting predicted distribution of PPR outbreaks' density is shown in Fig. 3. In general, the model demonstrates good agreement with the distribution of PPR outbreaks in China, 2007-2020, and suggests overall lower suitability to the PPR spread in Kazakhstan as compared to China.

$<$ Figure 3 about here $>$

Creating a risk map for the Republic of Kazakhstan

Allocation of the territory of Kazakhstan from the obtained model allows constructing a risk map specific for the RK (Fig. 4).

$<$ Figure 4 about here $>$

This map shows the increased expected density of outbreaks in areas along the western and especially southeastern borders of the RK. These areas are characterized by a higher density of small ruminants (Fig. 1). In particular, Turkistan, Zhambyl and Almaty regions are historically leading areas in terms of the small ruminants breeding. In these areas, there is also a high probability of the importation of the disease from the border regions of Turkmenistan, Kyrgyzstan and Uzbekistan, which are characterized by a high density of the small ruminants and the presence of sporadic outbreaks in the past.

\section{Model limitations}

The constructed model demonstrates satisfactory yet not very high ability to explain variation of the input data, which can be partly explained by the need of extrapolation of dependencies obtained for another country to the territory of Kazakhstan that was determined by the absence of PPR outbreaks in the RK, which could be used for direct model validation. The geographical and socio-economic risk factors used in the model are the most general indicators and, perhaps, not exhaustive for explaining the observed patterns of the epizootic situation in China. Since PPR does not belong to environmental diseases, the registration of outbreaks and the spread of the disease depends to a large extent on the transmission of the virus during transport links, interstage and interfermal contacts, which can be introduced into the model only indirectly through the geographical factors used. As another model limitation, we can mention that the data on PPR outbreaks in China may be incomplete due to possible underreporting of PPR from less populated prefectures of central and western parts of the country.

It should also be noted that the information of small ruminants' population distribution used for modeling is the most accurate and relevant for the Republic of Kazakhstan, since it was obtained by direct collection of georeferenced data in 2018 - 2019, while for China we used modelled data obtained by the dasymetric mapping based on 2010 national survey results.

In general, it can be noted that the created model demonstrates reasonable distribution of PPR spread risks across the RK districts that would be expected based on the information on the density of small ruminants' population and intensity of economic links, and thus can be used by the national veterinary authorities as a scientific support of the national strategy of PPR prevention. Development of a more accurate risk assessment study, as well as assessing the pathways of possible importation of the disease require building a more comprehensive model and taking into account a larger number of factors, both landscape and socioeconomic (in particular, building a network on animal movements requires movements data that are not currently collected in the RK on a regular basis), as well as knowledge of the current epizootic situation and the results of monitoring studies on PPR in countries bordering the Republic of Kazakhstan.

\section{Conclusion}

Our study presents a first ever attempt of assessing the risks of Peste des petits ruminants spread in the Republic of Kazakhstan based on some most general socio-economic and landscape indicators. The analysis entirely performed within ArcGIS software environment demonstrated a higher vulnerability of Kazakhstan districts along south-eastern and northern borders to the PPR spread in case of its introduction that corresponds to logical expectations based on the higher small ruminants' density and denser socio-economic 
links. The study also introduces the newly created national wise database on small ruminants' population distribution that may be further used

\section{Acknowledgements}

The work has been conducted as a part of scientific researches of the Agro-Industrial Complex under a Scientific-Technical program "Scientific basics of the veterinary wellbeing and food safety", the budgetary program \#267, Research Project BR06249242.

\section{Conflict of interests}

The authors declare no conflicts of interests with regard to this study.

\section{Ethics statement}

The authors confirm that the ethical policies of the journal, as noted on the journal's author guidelines page, have been adhered to. No ethical approval was required as this article does not include any research on live animals neither biological samples.

\section{Data Availability Statement}

The data on small ruminants' population in Kazakhstan that support the findings of this study are available on request from the corresponding author. The data are not publicly available due to privacy or commercial restrictions.

\section{Authors' contribution}

SKA - study conceptualization and design, project management, writing and reviewing; YYM, GNY, SNB, AN, AAA - data collection and analysis; AAS - grant acquisition; AP - data analysis, reviewing; FIK data analysis, visualization, writing and editing. All authors have read and agreed to the published version of the manuscript.

\section{List of references}

1. Amirbekov, M., A.O. Abdulloev, M. Anoyatbekov, A.M. Gulyukin, and A.D. Zaberezhny, 2020: Incidence and identification of peste des petits ruminants virus in Tajikistan. In: IOP Conf. Ser. Earth Environ. Sci.

2. Balamurugan, V., D. Hemadri, M.R. Gajendragad, R.K. Singh, and H. Rahman, 2014: Diagnosis and control of peste des petits ruminants: a comprehensive review. Virus Disease. DOI: 10.1007/s13337013-0188-2.

3. Bardhan, D., S. Kumar, G. Anandsekaran, J.K. Chaudhury, M. Meraj, R.K. Singh, M.R. Verma, D. Kumar, N. Kumar, S.A. Lone, V. Mishra, B.S. Mohanty, N. Korade, and U.K. De, 2017: The economic impact of peste des petits ruminants in India. OIE Rev. Sci. Tech. DOI: 10.20506/rst.36.1.2626.

4. Bouchemla, F., Agoltsov, V.A., Popova, O.M., Padilo, L.P., 2018. Assessment of the peste des petits ruminants world epizootic situation and estimate its spreading to Russia, Veterinary World, 11(5): 612-619.

5. Bouchemla, F., V.A. Agoltsov, O.M. Popova, and L.P. Padilo, 2018: Assessment of the peste des petits ruminants world epizootic situation and estimate its spreading to Russia. Vet. World. DOI: 10.14202/vetworld.2018.612-619.

6. Center for International Earth Science Information Network - CIESIN - Columbia University. 2018. Gridded Population of the World, Version 4 (GPWv4): Population Density, Revision 11. Palisades, NY: NASA Socioeconomic Data and Applications Center (SEDAC).https://doi.org/10.7927/H49C6VHW. Accessed 20.06.2020

7. Fine, A.E., M. Pruvot, C.T.O. Benfield, A. Caron, G. Cattoli, P. Chardonnet, M. Dioli, T. Dulu, M. Gilbert, R. Kock, J. Lubroth, J.C. Mariner, S. Ostrowski, S. Parida, S. Fereidouni, E. Shiilegdamba, J.M. Sleeman, C. Schulz, J.-J. Soula, Y. Van der Stede, B.G. Tekola, C. Walzer, S. Zuther, F. Njeumi, 
and Meeting Participants, 2020: Eradication of Peste des Petits Ruminants Virus and the WildlifeLivestock Interface . Front. Vet. Sci. 7, 50. DOI: 10.3389/fvets.2020.00050

8. Fotheringham, Stewart A., Chris Brunsdon, and Martin Charlton. Geographically Weighted Regression: the analysis of spatially varying relationships. John Wiley \& Sons, 2002.

9. Geographical distribution of PPR. - URL: http://www.oie.int/animal-health-in-the-world/pprportal/distribution/ (accessed: 15.07.2020).

10. Global Strategy for the Control and Eradication of PPR. URL:http://www.fao.org/emergencies/resources/documents/resources-detail/it/c/282777/. (accessed: 15.07.2020).

11. Global Strategy for the Control and Eradication of PPR. - URL: http://www.fao.org/emergencies/resources/documents/ resources-detail/it/c/282777/.

12. https://www.oie.int/wahis_2/public/wahid.php/Diseaseinformation/WI. (accessed: 15.07.2020).

13. Jones, B.A., K.M. Rich, J.C. Mariner, J. Anderson, M. Jeggo, S. Thevasagayam, Y. Cai, A.R. Peters, and P. Roeder, 2016: The economic impact of eradicating peste des petits ruminants: A benefit-cost analysis. PLoS One. DOI: 10.1371/journal.pone.0149982.

14. Kihu, S.M., G.C. Gitao, L.C. Bebora, N.M. John, G.G. Wairire, N. Maingi, and R.G. Wahome, 2015: Economic losses associated with Peste des petits ruminants in Turkana County Kenya. Pastoralism. DOI: 10.1186/s13570-015-0029-6.

15. Kock, R.A., M.B. Orynbayev, K.T. Sultankulova, V.M. Strochkov, Z.D. Omarova, E.K. Shalgynbayev, N.M. Rametov, A.R. Sansyzbay, and S. Parida, 2015: Detection and Genetic Characterization of Lineage IV Peste Des Petits Ruminant Virus in Kazakhstan. Transbound. Emerg. Dis. DOI: $10.1111 /$ tbed.12398.

16. Koshemetov, Z., A. Sansyzbay, N. Sandybayev, Y. Abduraimov, V. Matveyeva, S. Nurabayev, M. Bogdanova, G. Sugirbaeva, A. Burabaev, and M. Yessirkepov, 2014: Peste des petits ruminants: Monitoring, diagnostic and spread on the territory of the central Asia. Life Sci. J.

17. Ma, J., X. Gao, B. Liu, H. Chen, J. Xiao, and H. Wang, 2019: Peste des petits ruminants in China: Spatial risk analysis. Transbound. Emerg. Dis. DOI: 10.1111/tbed.13217.

18. Ma, J., X. Jianhua, L. Han, G. Xiang, C. Hao, and W. Hongbin, 2017: Spatiotemporal pattern of Peste des petits ruminants and its relationship with meteorological factors in China. Prev. Vet. Med. DOI: 10.1016/j.prevetmed.2017.09.009.

19. Mahapatra, M., S. Parida, M.D. Baron, and T. Barrett, 2006: Matrix protein and glycoproteins F and $\mathrm{H}$ of Peste-des-petits-ruminants virus function better as a homologous complex. J. Gen. Virol. DOI: 10.1099/vir.0.81721-0.

20. Mitchell, Andy. The ESRI Guide to GIS Analysis, Volume 2. ESRI Press, 2005.

21. Mokhtari, A., Z. Azizi, and S. Rabiaee Fradonbeh, 2017: Epidemiological study and spatial modeling of peste des petits ruminants (PPR) in central area of Iran. Rev. MVZ Córdoba. DOI: 10.21897/rmvz.1026.

22. Robinson, T., Franceschini, G., Wint, G.R.W., 2007. The food and agriculture organization's gridded livestock of the world. Vet. Italiana. Vol. 43. P. 745-751

23. Ruget, A.S., A. Tran, A. Waret-Szkuta, Y.O. Moutroifi, O. Charafouddine, E. Cardinale, C. CêtreSossah, and V. Chevalier, 2019: Spatial Multicriteria Evaluation for Mapping the Risk of Occurrence of Peste des Petits Ruminants in Eastern Africa and the Union of the Comoros. Front. Vet. Sci. DOI: $10.3389 /$ fvets.2019.00455.

24. Yapici, O., O. Bulut, O. Avci, M. Kale, M. Tursumbetov, S. Yavru, A. Simsek, and K. Abdýkerimov, 2014: First report on seroprevalence of bluetongue, border disease and peste des petits ruminants virus infections in sheep in Kyrgyzstan. Indian J. Anim. Res. DOI: 10.5958/0976-0555.2014.00013.2.

25. Zheng Cao, Yanzhi Jin, Tongtong Shen, Feibo Xu, Yanfei Li. Risk factors and distribution for Peste des petits ruminants (PPR) in Mainland China. Small Ruminant Research, 2018.162 (12-16), ISSN 0921-4488,https://doi.org/10.1016/j.smallrumres.2017.08.018.

26. Zhuravlyova, V.A., A. V. Lunitsin, A. V. Kneize, A.G. Guzalova, and V.M. Balyshev, 2020: Epizootic situation and modeling of potential nosoareals of peste des petits ruminants, sheep and goat pox and 
rift valley fever up to 2030. Sel'skokhozyaistvennaya Biol. DOI: 10.15389/agrobiology.2020.2.343eng.

\section{List of tables}

Table 1. Candidate explanatory variables and data sources

\begin{tabular}{|c|c|c|}
\hline Variable & Measurement units & Data sources \\
\hline Road length & $\mathrm{km}$ & $\begin{array}{l}\text { Esri Data and Maps: } \\
\text { https://www.arcgis.com/home/item.html? } i d=8353\end{array}$ \\
\hline Road density & $\mathrm{km}^{-1}$ & $\begin{array}{l}\text { Esri Data and Maps: } \\
\text { https://www.arcgis.com/home/item.html? } i d=8353\end{array}$ \\
\hline Small ruminants density & head $/ \mathrm{km}^{2}$ & $\begin{array}{l}\text { For China: FAO Gridded } \\
\text { Livestock of the World (Robinson } \\
\text { et al., 2010) } \\
\text { http://www.fao.org/geonetwork/srv/en/main.hom } \\
\text { For Kazakhstan: national survey } \\
\text { data described below }\end{array}$ \\
\hline Cattle density & head $/ \mathrm{km}^{2}$ & $\begin{array}{l}\text { FAO Gridded Livestock of the } \\
\text { World (Robinson et al., 2010) } \\
\text { http://www.fao.org/geonetwork/srv/en/main.hom }\end{array}$ \\
\hline Population density & person $/ \mathrm{km}^{2}$ & $\begin{array}{l}\text { Gridded Population of the World } \\
\text { (GPW), v4 (Center for } \\
\text { International Earth Science } \\
\text { Information Network, 2018) } \\
\text { https://sedac.ciesin.columbia.edu/data/set/gpw- } \\
\text { v4-population-count-rev11/data- } \\
\text { download }\end{array}$ \\
\hline Elevation & $\mathrm{m}$ & $\begin{array}{l}\text { USGS EarthExplorer: } \\
\text { https://earthexplorer.usgs.gov/ }\end{array}$ \\
\hline Annual mean temperature & ${ }^{\circ} \mathrm{Cx} 10$ & $\begin{array}{l}\text { WorldClim } 2 \text { (Fick and Hijmans, } \\
\text { 2017) https://worldclim.org/ }\end{array}$ \\
\hline Annual precipitation & $\mathrm{mm}$ & $\begin{array}{l}\text { WorldClim } 2 \text { (Fick and Hijmans, } \\
\text { 2017) https://worldclim.org/ }\end{array}$ \\
\hline $\begin{array}{l}\text { Maximum green vegetation } \\
\text { fraction }\end{array}$ & proportion & $\begin{array}{l}\text { Broxton et al., } 2014 ; \\
\text { https://archive.usgs.gov/archive/sites/landcover.u } \\
\text { veg.html }\end{array}$ \\
\hline
\end{tabular}

Table 2. Regression models' statistical metrics

\begin{tabular}{lll}
\hline & OLS & GWR \\
\hline AIC & 262,4 & 263,9 \\
Adjusted R & 0,61 & 0,61 \\
Moran's I z-score & 0,20 & $-0,16$ \\
Moran's I p-value & 0,84 & 0,87 \\
\hline
\end{tabular}

Table 3. Regression coefficients of the Ordinary Least Squares (OLS) model

\begin{tabular}{llll}
\hline Variable & Coefficient & Standard Error & Standardized Coefficient \\
\hline Intercept & -11.429 & 0.300 & 0
\end{tabular}




\begin{tabular}{llll}
\hline Variable & Coefficient & Standard Error & Standardized Coefficient \\
\hline MGVF & 0.018 & 0.003 & 0.374 \\
Road length & $-7.55 \mathrm{E}-4$ & $1.42 \mathrm{E}-4$ & -0.310 \\
Small ruminants' density & 0.005 & 0.001 & 0.287 \\
Annual mean temperature & 0.005 & 0.001 & 0.268 \\
Road density & 9.264 & 2.464 & 0.250 \\
Cattle density & -0.005 & 0.003 & -0.124 \\
\hline
\end{tabular}

List of figuresFig. 1. Republic of Kazakhstan: first- and second-level administrative divisions, small ruminants' population density and location of small ruminants' farmsFig. 2. Distribution of Peste des petits ruminants (PPR) outbreaks in China, 2007 - 2020. Data source FAO EMPRES-i.Fig. 3. PPR outbreak density model fitted to the entire study area (China and Kazakhstan)Fig. 4. Predicted PPR outbreak density in RK
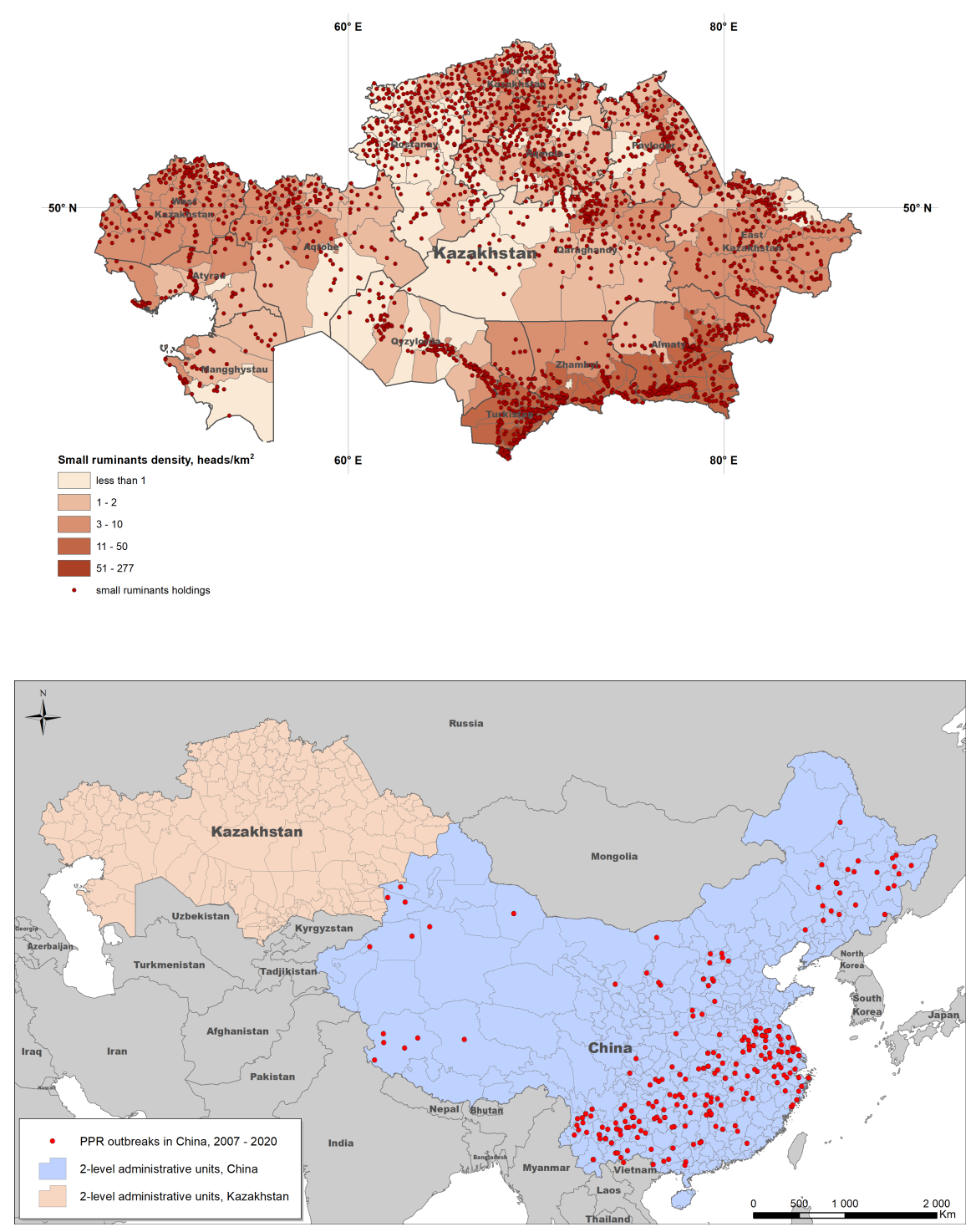

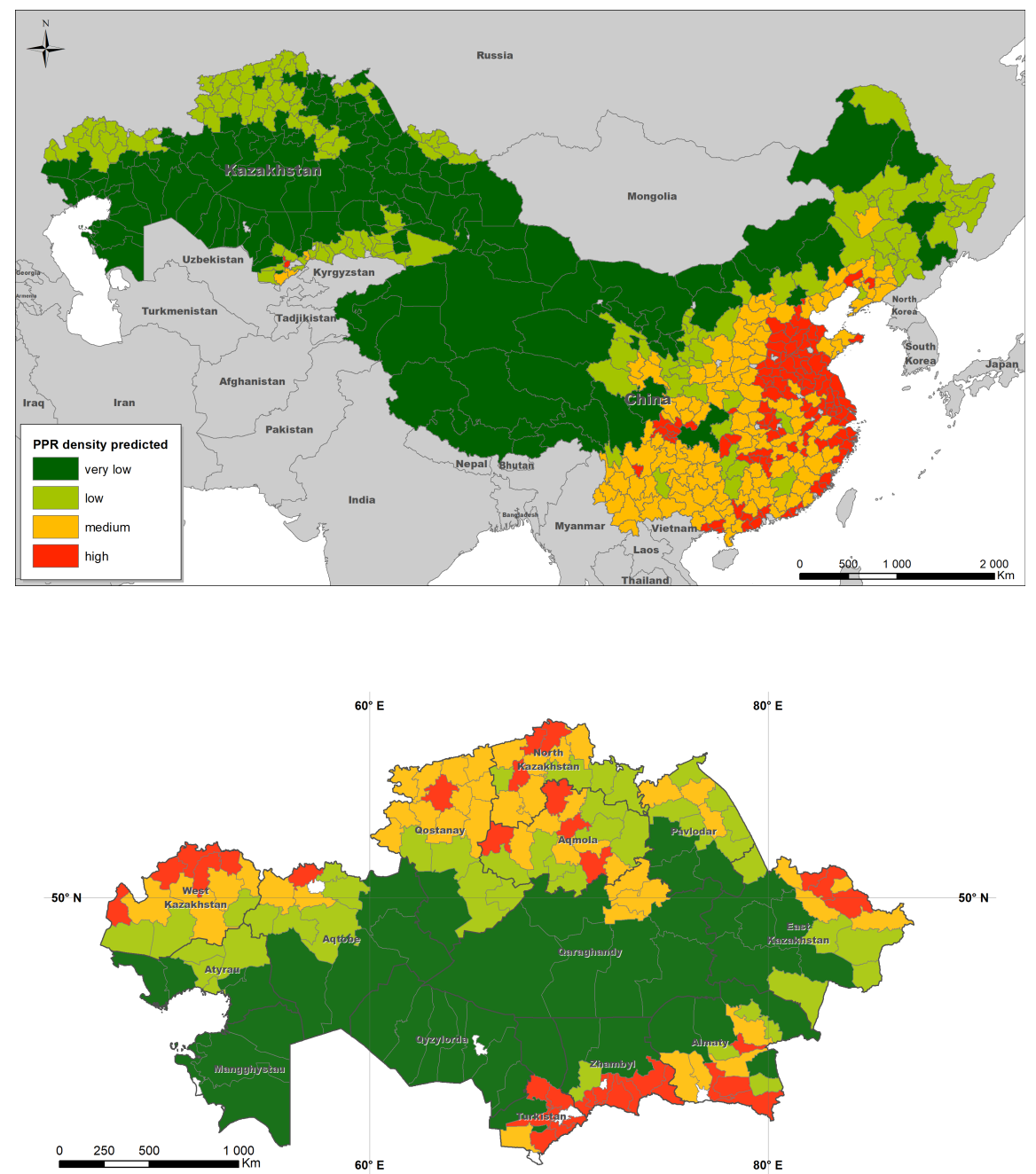

Risk of PPR spread

\begin{tabular}{|l}
\hline very low \\
low \\
medium \\
high
\end{tabular} 